\title{
PHYSIOLOGICAL EFFECTS OF PANDEMIC COVID-19 ON CHILDREN WITH AUTISM SPECTRUM DISORDER IN BANGLADESH
}

\author{
Sonia Sultana ${ }^{1}$ \\ Tawhida Jahan ${ }^{2}$
}

\begin{abstract}
Novel Coronavirus (Covid-19) pandemic is considered as the most challenging and life-threatening condition in today's world. It has been evident that children with autism spectrum disorder (ASD) face double challenge during the pandemic situation due to disrupted routine and unavailability of therapy resulting in some new adopted physiological symptoms that increases the risk of getting infected with corona virus. So, this study aims to find out the nature and causes of the physiological effects of Covid 19 pandemic on children with autism and at the same time suggest taking the proper action regarding these physiological phenomena reducing the of rate of vulnerability. The participants of this study are the parents and the therapists of the children (age range: 5-15 years) with ASD who have been chosen purposefully from Dhaka and Chattogram divisions, Bangladesh. Data has been collected from the participants with the questionnaire and focus group discussion tools through online platform zoom cloud. Results demonstrates that most of the children have an increase in body weight, reduced energy burning, and sleep disturbances since lockdown started that further worsen their hyperactivity suggesting the necessity of acting for the awareness of parents group and thus prevention of covid-19 among children with ASD.
\end{abstract}

Keywords: Novel Coronavirus (Covid-19), physiological effects, autism spectrum disorder (ASD), pandemic, Bangladesh

\section{Introduction}

Pandemic Novel Coronavirus (Covid-19) is going on all over the world as well as in Bangladesh since 8th March 2020. This pandemic affects the normal way of

1 Sonia Sultana, is Doctor \& Consultant, Communication Disorders, BRB Hospitals Limited, Dhaka, Bangladesh. Email: drsoniasultana@yahoo.com

2 Tawhida Jahan, is Chairperson \& Assistant Professor, Department of Communication Disorders, University of Dhaka, Bangladesh. Email: tawhida.jahan@du.ac.bd

Social Science Review [The Dhaka University Studies, Part-D], Vol. 38, No. 1, June 2021

DOI: https://doi.org/10.3329/ssr.v38i1.56531 
life of most of the population. In this circumstance, children are compromising their regular lifestyle in almost every step of their life and adopting themselves at home quarantine for a long period of time. Even typically developed children are losing their patience become intolerant to new normal life, where children with disabilities have already faced significant challenges during Covid 19 pandemic. So, we need to find out the full effect of pandemic for individual with disabilities (Baweja, Brown, Edwards \& Murray, 2021). Researcher found that, often infectious disease like covid 19 pandemics are associated with adverse psychological and behavioural responses such as, increased stress and depression, sleep disturbance, reduced feelings of safety (Brooks et al., 2020; Morganstein, Fullerton, Ursano, Donato \& Holloway, 2017).

Autism Spectrum Disorder (ASD) is a neurodevelopmental disorder characterized by difficulties in social interaction and restricted repetitive behaviour. (American Psychiatric Association. Diagnostic and Statistical Manual of Mental Disorders, 2013.) ASD has a wide range symptom. These symptoms consist of socialization, communication, limited social skills, behavioural and interest impairments (Weiss, \& Lunsky, 2011). Because of these symptoms, children with ASD may have trouble relating to peers and forming relationships. Besides, Parents of children with ASD also experience prolonged levels of stress and isolation from society which is very common in the southeast Asian region (Luong, Yoder, \& Canham, 2009). This scenario is not different for Bangladesh. Even in corona pandemic, situation is more worser than other time. Since Autism is a social communication disorder, child with ASD cannot understand their surrounding context and has difficulty to adapt in any new normal situation. In present lock down situation, children with ASD are vulnerable to condition of a long isolation due to their limitation of coping new situation, adapting new routines, and receiving treatments. These reasons negatively affect their progress (Amaral \& de Vries, 2020). That is why children with ASD are especially at high risk for developing new symptoms as they are dependent on behavioural and other therapeutic intervention for improving communication, forming relationships, decreasing repetitive behaviour and developing independence (Larsson, 2005) which cannot be provided in this adverse condition. Whenever they are not getting these therapies, hyperactive behaviours as well as some physiological changes are developing in children with autism which are very common scene in doctor's chamber now a day. 
On the other hand, taking care of a neuro-atypical child for 24 hours is not an easy job to do. Most of the time parents of children with ASD remain anxious for their kids. They become depressed because of the unwanted social circumstances. Moreover, in present corona lockdown situation parents of these children must bear with financial challenges, mental overstress, social distancing with friends and relatives for last one year which make them tried to handle their children with ASD.

It is important to mention that, developmentally challenged children like children with autism have relatively poor immunological status. Researchers found that, children with ASD have reduced immune system. This immune deregulation appears to facilitate increased inflammation and may be linked to the gastrointestinal issues, allergies, asthma, or some other form (Rose et. al., 2018), which makes ASD children are venerable to Covid 19.

Also, at least half of the children with autism have intellectual disabilities; those who belong in normal IQ range even though they may have significant language and communication deficits (Mody \& Belliveau, 2013). Because of that, sometimes they could not be able to follow the instruction for maintaining health hygiene and failed to understand the necessity of washing hands or wearing mask. Those reasons influence the chance of getting infected by covid-19 virus is more in children with ASD than typically developed children. In this regard, it is a matter of high importance to find out the severity of the altered body physiology during this pandemic Covid-19 so that we can be cautious to protect them.

So, the objectives of the current study are: a) to find out the adverse physiological effects of covid-19 pandemic on children with ASD in Bangladesh; b) to find out the real cause behind the altered body physiology of ASD children; and c) to suggest the probable remedy or treatment plan for children with ASD.

\section{Literature Review}

An outbreak of the 2019 Novel Coronavirus (Covid-19) has been ongoing in China since January 2020. In Bangladesh first covid-19 positive patient was identified on $8^{\text {th }}$ March 2020 (Sakib, 2020). The lockdown situation, due to the threat of infection the work and life of most of the population may also hampered. As example by Colizzi et al. (2020) where they said, incidence like Covid-19 outbreak has an adverse effect on physical and mental health 
increasing the fear and concerns and if it is for those human beings who are regarded as vulnerable then the risk is higher. Autistic individuals as consideration, to maintain quarantine can possibly raise the chances to suffer with those issues of health (Brooks et al., 2020). As mentioned by Greenberg, Seltzer, Hong \& Orsmond (2006) that being quarantined due to Covid-19 outbreak, a highly emotional situation, can result in an increased level of maladaptive behaviour of ASD children. It is imperative to say by getting informed form Seltzer \& Krauss (2001) and Drogomyretska, Fox \& Colbert (2020) that, the rate of stress experienced by the family of ASD individuals is way more dense than other disorders. Though, in the initial period of Covid-19 outbreak, it was assumed that children are of less risk of getting infected also a mild disease (Riphagen, Gomez, Gonzalez-Martinez, Wilkinson \& Theocharis, 2020) but ASD children of higher healthcare needs, dependency to community-based services and issues of mental health changed that perception by increasing the rate and impact.

So, ASD are a group of conditions characterized by social communication problems, difficulties with reciprocal social interactions, and unusual patterns of repetitive behaviour (American Psychiatric Association, 2013). With this underlying symptom, in a situation like the outbreak of Covid-19 undoubtedly increases the rate of getting stressed, anxious, or confused of ASD individuals (Baron-Cohen. 2006) and among all disorders, ASD individuals are certainly needed to provide proper intervention regarding these issues (Narzisi, 2020). ASD individuals who are to follow a daily routine to lead life, any changes to this routine can make difficult to adopt due to their behavioural issues as Covid-19 outbreak did (American Psychiatric Association, 2013; Narzisi, 2020). As mentioned before, parents of children with ASD are found of having higher levels of stress and, also to report, the rate of divorce among parents of children with ASD are on rise due to the difficulties and challenges faced by them to raise their children (Rivard, Terroux, Parent-Boursier \& Mercier, 2014).

All the above factors discussed here cause change in certain physiological phenomenon in children with autism spectrum disorder during the Covid-19 outbreak. The researcher wants to find out those physiological changes to take proper preventive methods in future. 


\section{Methodology}

The objectives of the study were to find out the altered physiological mechanism in children with ASD as well as to discuss the ways to overcome this problem with expert therapists so that we can take necessary clinical measures for the Bengali children with ASD. To get a more valid result this study followed a longitudinal design over a year since the pandemic started.

The participants of this study have been chosen purposefully from two renowned special schools of Dhaka and Chittagong cities named Proyash and Ashar Alo in Bangladesh. As one of the researchers was personally attached with both the institutions (ex-principle, Ashar Alo and adjunct faculty Proyash), it was easy to collect data from the parents and therapists of these special schools. They are of 5 to 15 years age groups and with autism spectrum disorder; chosen by following the criteria of DSM-5 (American Psychiatric Association, 2013). As they were already diagnosed case by experts of the school authority at the time of their admission, further diagnosis was not needed by the researcher. Children with other disabilities have been excluded from the study.

Data has been collected from online zoom meeting and telephone conversation with the parents and the therapists of the children with ASD. The perception survey questionnaire has been given to the parents which they returned after 15 days. To get more detail information focus group discussion in online zoom meeting has been conducted. Moreover, telephone conversation with the therapists of Proyash and Asher Alo schools added some valuable data to the study.

The perception survey questionnaire had two major parts. The first part deals with the personal details of the participants while the second part deals with the attributing statements about sleep disturbance, physical exercise patterns, dietary plan, change of body weight, sensory problem etc. Likert Scale has been used for calculating the response rate.

Moreover, Focus Group Discussions (FGD) with about 80 parents provides more detailed idea about their new experience regarding the physiological effects of the Covid-19 among children with ASD. Five parents' group (15-18 parents each group) took part in the online FGDs in different time because of the pandemic situation. However, the summary of focused group discussions has been discussed in the result section. 


\section{Results}

Perception survey, focused group discussion, telephone conversation with the therapists and review of literatures has been applied to get a more acceptable result for the current study.

The perception survey study has been taken among 110 parents to observe their views. It has five attributing statements which reflect the degree of severity of physiological changes in children with ASD. The responses of the perception survey study have been calculated using the Likert response scale which is described in the following table.

Table 1: Demonstrating the attributing factors of the perception survey

\begin{tabular}{ll}
\hline $\begin{array}{l}\text { Serial } \\
\text { no. }\end{array}$ & Topic of the statement \\
\hline 1st & $\begin{array}{l}\text { Sleep pattern of your child during last } 6 \text { months has been changed } \\
\text { or remain unchanged. }\end{array}$ \\
\hline 2nd & $\begin{array}{l}\text { Physical exercise of your child has been reduced since lockdown } \\
\text { started. }\end{array}$ \\
\hline 3rd & Aggravating the sensory issues in your child during last 6 months. \\
\hline 4th & Any change in food habit (menu or in amount) for last six months. \\
\hline 5th & $\begin{array}{l}\text { Changes in body weight (overweight/weight loss) has been } \\
\text { observed in your child. }\end{array}$ \\
\hline
\end{tabular}

Sleeping pattern, energy expenditure, increasing the severity of previous sensory disturbance or development of new sensory issues, diet change and weight gaining during the lockdown period are included in the attributing statements with three probable answers showing the severity of changes where: No change $=$ 1 , mild change $=2$ and severe change $=3$.

Table 2: Illustrating the results of the perception survey

\begin{tabular}{llll}
\hline $\begin{array}{l}\text { Number of } \\
\text { statements }\end{array}$ & $\begin{array}{l}\text { No change at all } \\
\text { (1) }\end{array}$ & Mild Change (2) & Severe Change (3) \\
\hline 1st & $24 \times 1=24$ & $46 \times 2=92$ & $40 \times 3=120$ \\
\hline
\end{tabular}




\begin{tabular}{llll}
\hline 2nd & $10 \times 1=10$ & $31 \times 2=62$ & $69 \times 3=207$ \\
\hline 3rd & $45 \times 1=45$ & $38 \times 2=76$ & $27 \times 3=81$ \\
\hline 4th & $33 \times 1=33$ & $45 \times 2=90$ & $32 \times 3=96$ \\
\hline 5th & $49 \times 1=49$ & $34 \times 2=68$ & $27 \times 3=81$ \\
\hline
\end{tabular}

Results showing from the Table 2, 40 parents of children with ASD stating severe change in sleeping patterns of their children during last 1 year, 46 stating mild change while only 24 parents said their children faced no such issue. Parents commenting on the reduction of physical exercise of their children with ASD, a significant outcome came up showing 69 parents stating severe change in the reduction of physical exercise faced by their children while 31 stating mild change and only 10 children had no such issue said by their parents. Children with ASD facing new sensory issues depicted that only 27 children faced severe sensory issues, 38 and 45 for mild and no change respectively stated by the parents. While we analyse the changes in food habit for last six months, we find that 32 parents stated about their children facing sever change, 45 and 33 for mild and no change, respectively. Lastly, results from the changes in body weight shows 27 parents stating sever change in body weight faced by their children while 34 faced mild change and 49 had no such issue.

It has been observed from the survey that in almost every physiological aspect there are some changes demonstrating that Covid-19 has altered most of the normal body phenomenon in children with ASD. The average result of each attributing statement has been calculated and described in the following pie-chart.

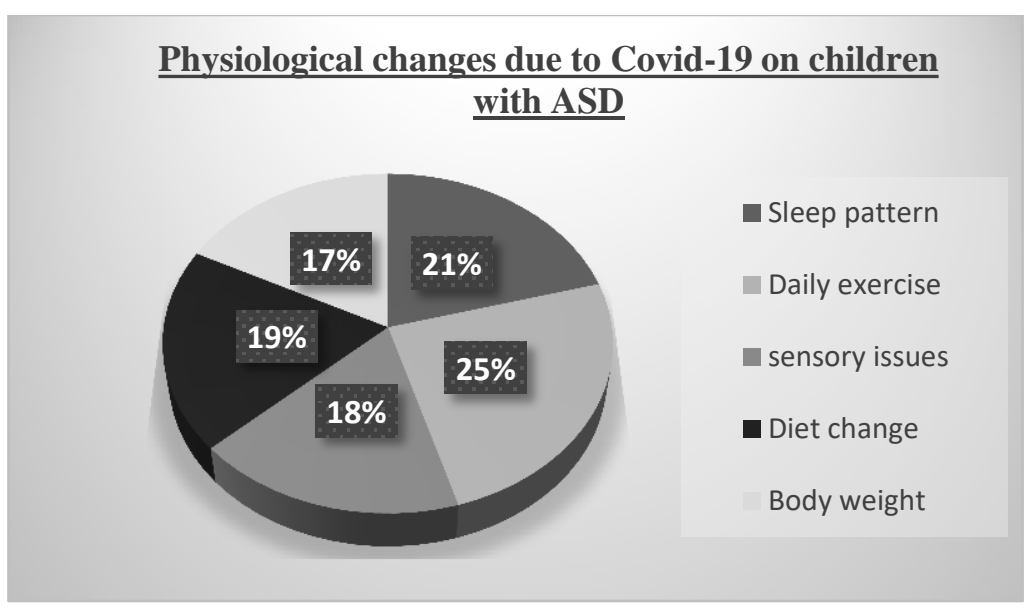

Fig.1: Pie-chart showing average changes in different physiological process caused by covid-19 on children with Autism spectrum disorder (ASD) 
Table3: Demonstrating the number of children with ASD showing changes in different phenomenon

\begin{tabular}{lccc}
\hline Likert response scale & & & \\
\hline $\begin{array}{l}\text { Physiological } \\
\text { phenomenon }\end{array}$ & No change & Mild change & Severe change \\
Sleep pattern & 24 & 46 & 40 \\
Daily exercise & 10 & 31 & 69 \\
Sensory issues & 45 & 38 & 27 \\
Diet change & 33 & 45 & 32 \\
Body weight & 49 & 34 & 27 \\
\hline
\end{tabular}

More detailed result from the perception survey has been illustrated in the bar diagram in which the maximum change is in the daily exercise.

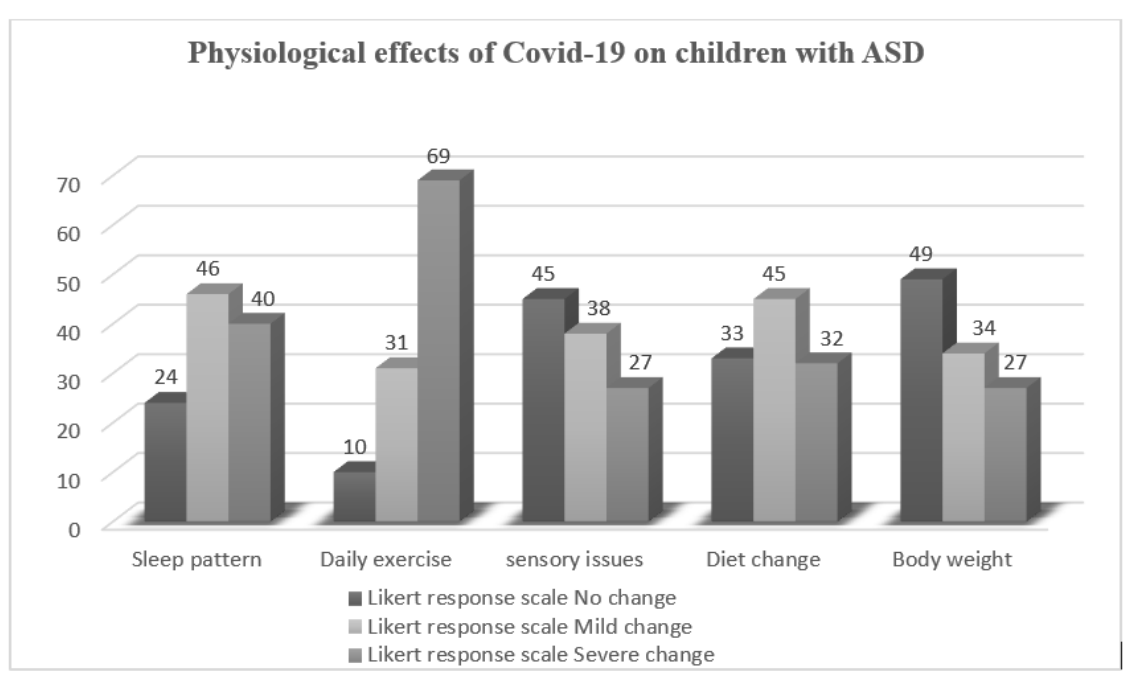

Fig. 2: Illustrating physiological effects of covid 19 with severity.

In the focus group discussion, Parents of the children with ASD was divided into five groups for the online zoom meeting. Problems they suffered due to the present lock down situation has been discussed in detail. Most of the parents complained about aggravation of hyperactivities of their children with ASD since Covid-19 outbreak. Some of them also mentioned about developing some new 
sensory issues. Some of the parents were in tension about the diet and body weight of their children. Most of the parents complain about sleep disturbance of their children which is more severe than a typically developed child. Recommendation from parents to overcome the altered physiology of their children has also been discussed. Very few of them agreed that if they change their lifestyle a bit thing can be changed. But most of the parents need a motivational counselling as they become frustrated by the circumstances.

Telephone conversation with 8 therapists from two special schools enrich the study because of the practical experiences shared by them. Due to the lockdown condition face to face conversation cannot be possible. The view of the therapist regarding alteration of normal physiology was almost similar with the parents group. Advice from the therapists for the probable solution of the problems made the study more authentic. Most of them recommend for regular parent counselling as they played most important role to handle their child. Supervision by the special educators and therapists through video conversation was also recommended. Regular health check-up, balanced diet, physical exercise is also very important according to their view. Some of the therapists also advised to go outside with proper precaution at least twice in a week. Overall conversation with the therapists was helpful for the researcher to get some tips to prevent the unwanted physiological effects.

\section{Discussion}

We are now living in a great uncertainty due to the Covid-19 pandemic, and the need to stay physically distant from each other, has required us to make very rapid changes to our everyday lives. The impact of the pandemic will likely be even more dangerous for children with autism spectrum disorder. Unavailability of regular therapy, breakup of routine life, lack of physical exercise and their behavioural limitations together make them vulnerable. Even in the United States, various challenges faced by individuals with ASD including disruptions caused by educational and vocational changes, challenges to daily routines, limited access to health care services due to the pandemic (Baweja, et.al., 2021). 
But the complete picture of the impact of pandemic covid-19 on children with autism at present is unknown due to deficient research work. In Bangladesh, there are very few studies on pandemic Covid-19 specially its effects on children with ASD. So, the current study is an important first step is to identify and discuss the pros and cons of lockdown situation on children with autism. We believe, to develop a better service system for ASD children, the first step is to identify the alteration in their physiological processes like speech, cognition, nutrition, sleep etc. so that we can prevent the damage before it is too late.

In this regard this exploratory study wanted to find out the negative effects of covid-19 pandemic on the normal physiology of children with ASD. As Brooks et al. 2020 mentioned the negative impact on health due to quarantine a similarity has been found observing maximum alteration in the daily exercise or energy burning due to the restriction of going outside. As a result, the extra energy produced in their body make them more hyperactive.

Besides, we also got informed from Narzisi, 2020 apprising about the risks of children with ASD for the changes in routine caused by Covid-19 outbreak supporting our finding that, the sleep pattern of children with ASD has also been altered due to the lazy day time without any activities that in turn alter their metabolic process and cause hormonal imbalance in their bodies. As a result, their dietary habit has been changed that might cause weight gaining in some children and weight losing in others. Almost every physiological process has been changed in this new normal situation caused by the pandemic.

The objective of this study was to find out the information from the stakeholders regarding the physiological alteration among children with ASD to provide them support from proper authority. Researcher believes that this maiden study regarding children with ASD in a pandemic condition in Bangladesh perspective must be helpful to the stakeholders of our country. However, interviewing the therapist and reviewing the previous studies gave the same results that makes this study more valid.

Perception survey and focused group discussion among the parents of children with ASD gave the researcher in- depth ideas and suggestions. Furthermore, interviewing the therapists over telephone has made the study more informative by giving ideas to manage these children with ASD in present new normal situation. According to therapist's view regular parents counselling, supervision 
by special educators and therapists through video conference, balanced diet and daily exercise are necessary for the wellbeing of children with ASD at present.

\section{Conclusion}

In closing, it can be said that alteration of physiological processes caused by pandemic situation in children with ASD can be prevented by taking appropriate approaches which initiate and increase their physiological development. Some of these changes in their body mechanism have been discussed with the stakeholders as well as the experts in this sector to get their views and opinions. For example, daily physical exercise, balanced diet, happy home environment has been suggested by the stakeholders whereas early diagnosis of the pathology and possible online intervention. Finally, the Government may build and enhance their training capacities by ensuring required number of qualified instructors to enrich the knowledge of the parents regarding proper handling of children with ASD in this new normal pandemic condition.

\section{Recommendation}

If parents are trained on child development by qualified instructor through online workshops and seminars, only then effective therapy could be provided by the parents most of the time in a day that might enhance the early recovery from the side effects of pandemic Covid-19. On the other hand, as almost all the physiological body mechanisms have direct relation with the physical exercise, children with ASD must have to do some heavy work to burn their extra energy. This will help them making calm down as well as establishing hormonal balance in their body. In total, a general awareness among the stakeholders as well as the government should be raised on management of these children with ASD in this new normal condition to reinforce their development so that we can turn them into our human resources.

\section{Acknowledgement}

All the parents of the children with ASD are the heart of the research for their active participation and experienced opinions. Special thanks to two specialized schools namely BN Ashar Alo, Chattogram and Proyash, Dhaka and the therapists because of their praiseworthy support to the researcher by giving information, data and selecting sample. 


\section{References}

American Psychiatric Association. (2013). Diagnostic and statistical manual of mental disorders, 5th edition: DSM-5 (5th ed.). American Psychiatric Publishing.

Amaral, D. G., \& de Vries, P. J. (2020). COVID-19 and autism research: Perspectives from around the globe. Autism Research, 13(6), 844-869. doi: 10.1002/aur.2329

Baron-Cohen, S. (2006). The hyper-systemizing, assortative mating theory of autism. Progress in Neuro-Psychopharmacology and Biological Psychiatry, 30(5), 865-872. doi: 10.1016/j.pnpbp.2006.01.010

Baweja, R., Brown, S. L., Edwards, E. M., \& Murray, M. J. (2021). COVID-19 pandemic and impact on patients with autism spectrum disorder. Journal of Autism and Developmental Disorders, 1-10. https://doi.org/10.1007/s10803-021-04950-9

Brooks, S. K., Webster, R. K., Smith, L. E., Woodland, L., Wessely, S., Greenberg, N., \& Rubin, G. J. (2020). The psychological impact of quarantine and how to reduce it: Rapid review of the evidence. The Lancet, 395(10227), 912-920. doi: 10.1016/s0140-6736(20)30460-8

Colizzi, M., Bortoletto, R., Silvestri, M., Mondini, F., Puttini, E., Cainelli, C., Gaudino, R., Ruggeri, M., \&Zoccante, L. (2020). Medically unexplained symptoms in the times of COVID19 pandemic: A case-report. Brain, Behavior, \& Immunity - Health, 5, 100073. doi: $\underline{10.1016 / \text { j.bbih. } 2020.100073}$

Drogomyretska, K., Fox, R., \& Colbert, D. (2020). Brief report: Stress and perceived social support in parents of children with ASD. Journal of Autism and Developmental Disorders, 50(11), 4176-4182. doi: 10.1007/s10803-020-04455-x

Greenberg, J. S., Seltzer, M. M., Hong, J., \& Orsmond, G. I. (2006). Bidirectional effects of expressed emotion and behavior problems and symptoms in adolescents and adults with autism. American Journal on Mental Retardation, 111(4), 229. doi: 10.1352/08958017(2006)111[229:BEOEEA]2.0.CO;2

Luong, J., Yoder, M. K., \& Canham, D. (2009). Southeast Asian parents raising a child with autism: A qualitative investigation of coping styles. The Journal of School Nursing, 25(3), 222-229.

Larsson, E. V. (2005). Intensive early intervention using behavior therapy is no longer experimental. Lovaas Institute for Early Intervention. Retrieved from http://rsaffran.tripod.com/ieibt.html (Accessed on May 25, 2005).

Seltzer, M., \& Krauss, M. W. (2001). Quality of life of adults with mental retardation/developmental disabilities who live with family. Mental Retardation and Developmental Disabilities Research Reviews, 7(2), 105-114. doi: 10.1002/mrdd.1015

Mody, M., \& Belliveau, J. W. (2013). Speech and language impairments in autism: insights from behavior and neuroimaging. North American journal of medicine \& science, 5(3), 157.

Morganstein, J. C., Fullerton, C. S., Ursano, R. J., Donato, D., \& Holloway, H. C. (2017). (2017). Pandemics: Health Care Emergencies. In Ursano, R. J., Fullerton, C. S., Weisaeth, L., \& Raphael, B. (Eds.), Textbook of Disaster Psychiatry (pp. 270-284). Cambridge: UK: Cambridge University Press. doi: 10.1017/9781316481424.019

Narzisi, A. (2020). Handle the autism spectrum condition during coronavirus (COVID-19) stay at home period: Ten tips for helping parents and caregivers of young children. Brain Sciences, 10(4), 207. doi: 10.3390/brainsci10040207 
Riphagen, S., Gomez, X., Gonzalez-Martinez, C., Wilkinson, N., \& Theocharis, P. (2020). Hyperinflammatory shock in children during COVID-19 pandemic. The Lancet, 395(10237), 1607-1608. doi: 10.1016/s0140-6736(20)31094-1

Rivard, M., Terroux, A., Parent-Boursier, C., \& Mercier, C. (2014). Determinants of stress in parents of children with autism spectrum disorders. Journal of Autism and Developmental Disorders, 44(7), 1609-1620. doi: 10.1007/s10803-013-2028-z

Rose, D. R., Yang, H., Serena, G., Sturgeon, C., Ma, B., Careaga, M., ... \& Ashwood, P. (2018). Differential immune responses and microbiota profiles in children with autism spectrum disorders and co-morbid gastrointestinal symptoms. Brain, behavior, and immunity, 70, 354368.

Sakib, S. N. (2020). Bangladesh confirms first case of coronavirus. Retrieved from https://www.aa.com.tr/en/asia-pacific/bangladesh-confirms-first-case-of-coronavirus/1758924?fbclid=IwAR3H7sLd7DYiVfvoYR-

Hc6ayzaE8Z7v6BCmA01w_blKrf0bq1qcLf_L9geM\# (Accessed on May 25, 2021).

Weiss, J. A., \& Lunsky, Y. (2011). The Brief Family Distress Scale: A measure of Crisis in caregivers of individuals with autism spectrum disorders. Journal of Child and Family Studies, 20(4), 521-528. doi: 10.1007/s10826-010-9419-y. 
